\title{
PERBANDINGAN ALGORITMA PADA VIRTUAL PRIVATE NETWORK IPSEC TERHADAP KECEPATAN DATA TRANSFER
}

\author{
${ }^{1}$ Alpan Hikmat Muharram Permana, ${ }^{2}$ Nur Widiyasono, ${ }^{3}$ Alam Rahmatulloh \\ 1,2,3 Jurusan Informatika Universitas Siliwangi Tasikmalaya \\ Jl. Siliwangi No. 24 Kahuripan Kec. Tawang Tasikmalaya Jawa Barat 46115 \\ Email : ${ }^{1}$ alpanhikmat@outlook.com, ${ }^{2}$ nur.widiyasono@unsil.ac.id, ${ }^{3}$ alam@unsil.ac.id
}

(Diterima: 3 Januari 2020, direvisi: 5 Mei 2020, disetujui: 7 Mei 2020 )

\begin{abstract}
VPNs can slow down internet connections because data must travel through the VPN network and encrypt and decrypt data that requires more time. Humans need a solution to make it easier in terms of obtaining the speed of time, security, reduce costs, and get the ease of communication without thinking about distant places. Several algorithms can be applied to VPN technology including AES, DES, 3DES, RC4, Blowfish and IDEA, but it is not yet known from these algorithms that the most optimal performance in terms of data transfer speeds. This research will compare algorithms on IPSec Virtual Private Network (VPN) technology to data transfer speeds using cisco packet tracer tools and only compare DES, 3DES, AES 128, AES 192 and AES 256 algorithms. The contribution of this study is to show that the 3DES algorithm as the most optimal algorithm in terms of data transfer speeds on files measuring 5571584 bytes with a ratio of $13.69 \%$ slower, files measuring 33591768 bytes with a ratio of $14.97 \%$ slower and on files measuring 16599160 bytes with a ratio of $8.36 \%$ slower on download process. While in the upload process, the file size is 5571584 bytes with a ratio of $11.17 \%$ slower, the file size is 33591768 bytes with a ratio of $11.66 \%$ slower and the file size is 16599160 bytes with a ratio of $9.05 \%$ slower.
\end{abstract}

Keywords: IPSec, Speed, Transfer, VPN

\begin{abstract}
ABSTRAK
VPN dapat memperlambat koneksi internet karena data harus melakukan perjalanan melalui jaringan VPN serta mengenkripsi dan mendekripsi data yang memerlukan lebih banyak waktu. Manusia membutuhkan sebuah solusi untuk mempermudah dalam hal memperoleh kecepatan waktu, keamanan, meringankan biaya, serta mendapat kemudahan berkomunikasi tanpa memikirkan tempat yang jauh. Ada beberapa algoritma yang dapat diterapkan pada teknologi VPN diantaranya yaitu AES, DES, 3DES, RC4, Blowfish dan IDEA, namun belum diketahui dari algoritma tersebut kinerja yang paling optimal dari segi kecepatan transfer data. Penelitian ini akan melakukan perbandingan algoritma pada teknologi Virtual Private Network (VPN) IPSec terhadap kecepatan transfer data menggunakan tools cisco packet tracer dan hanya membandingkan algoritma DES, 3DES, AES 128, AES 192 dan AES 256. Kontribusi penelitian ini adalah menunjukan bahwa algoritma 3DES sebagai algoritma yang paling optimal dari segi kecepatan transfer data pada file berukuran 5571584 bytes dengan rasio 13,69\% lebih lambat, file berukuran 33591768 bytes dengan rasio 14,97\% lebih lambat dan pada file berukuran 16599160 bytes dengan rasio 8,36\% lebih lambat pada proses download. Sedangkan pada proses upload, pada file berukuran 5571584 bytes dengan rasio 11,17\% lebih lambat, file berukuran 33591768 bytes dengan rasio 11,66\% lebih lambat dan pada file berukuran 16599160 bytes dengan rasio $9,05 \%$ lebih lambat.
\end{abstract}

Kata Kunci: IPSec, Kecepatan, Transfer, VPN

\section{PENDAHULUAN}

Virtual Private Network (VPN) berperan sebagai koneksi dimana data dienkapsulasi yang dikenal sebagai terowongan dan beberapa bagian dari koneksi yang dienkripsi atau disamarkan (obfuscated) [1]. Koneksi internet melalui penyedia layanan internet dan komputer server VPN dapat melayani kebutuhan jaringan jarak jauh ratusan atau ribuan client jarak jauh. Kelebihan menggunakan server VPN, administrator jaringan dapat memastikan bahwa hanya pengguna di jaringan organisasi 
yang memiliki izin yang sesuai yang dapat membuat koneksi VPN dengan server VPN dan mendapatkan akses ke sumber daya komputer yang dilindungi [2].

VPN dapat memperlambat koneksi internet karena data harus melakukan perjalanan melalui peladen VPN serta mengenkripsi dan mendekripsi data yang memerlukan lebih banyak waktu dan energi. Seiring berjalannya waktu, manusia membutuhkan sebuah solusi untuk mempermudah dalam hal memperoleh kecepatan waktu, keamanan data, meringankan biaya pengeluaran, serta mendapat kemudahan berkomunikasi tanpa memikirkan tempat yang jauh [3].

Berdasarkan survey Global Web Index 2018, menunjukan bahwa Indonesia merupakan pengguna $V P N$ terbesar di dunia yakni sebesar $44 \%$ dari daerah Asia Pasifik. Hal tersebut menjadikan Indonesia rentan terhadap resiko pembocoran data pribadi para pengguna ke pihak-pihak yang tidak bertanggung jawab [4].

Merujuk pada penelitian [5] membahas tentang algoritma keamanan pada VPN dan teknik enkripsinya. Algoritma yang digunakan pada penelitian tersebut yaitu AES, DES, 3DES, RC4, Blowfish dan IDEA menggunakan metode stream cipher dan protokol VPN IPSec, namun belum diketahui dari 6 algoritma tersebut kinerja yang paling optimal dalam segi kecepatan transfer data. Tujuan Penelitian ini adalah melakukan pengukuran transfer data pada proses download dan upload pada jaringan VPN IPSec dengan menerapkan algoritma : DES, 3DES, AES 128, AES 192 dan AES 256.

\section{TINJAUAN PUSTAKA}

Virtual Private Network (VPN) adalah sebuah teknologi komunikasi yang memungkinkan untuk dapat terkoneksi ke jaringan publik dan menggunakannya untuk dapat bergabung dengan jaringan lokal. Cara tersebut maka akan didapatkan hak dan pengaturan yang sama seperti halnya berada di dalam kantor atau LAN itu sendiri, walaupun sebenarnya menggunakan jaringan milik public [6].

IPSec (IP Security) adalah sebuah protokol yang digunakan untuk mengamankan transmisi datagram dalam sebuah internetwork berbasis TCP/IP. IPSec mendefiniskan beberapa standar untuk melakukan enkripsi data dan juga integritas data pada lapisan kedua dalam DARPA Reference Model (internetwork layer). IPSec melakukan enkripsi terhadap data pada lapisan yang sama dengan protokol IP dan menggunakan teknik tunneling untuk mengirimkan informasi melalui jaringan Internet atau dalam jaringan Intranet secara aman [6].

Kriptografi adalah ilmu mengenai teknik enkripsi dimana data diacak menggunakan suatu kunci enkripsi menjadi sesuatu yang sulit dibaca oleh seseorang yang tidak memiliki kunci dekripsi. Dekripsi menggunakan kunci dekripsi mendapatkan kembali data asli. Teknik enkripsi pada kriptografi klasik yang digunakan adalah enkripsi simetris dimana kunci dekripsi sama dengan kunci enkripsi [7].

DES menggunakan kunci sebesar 64 bit untuk mengenkripsi blok, tetapi karena 8 bit dari kunci digunakan sebagai parity, kunci efektif hanya 56 bit. Gambar 2.6 secara garis besar menunjukkan proses enkripsi DES. Penomoran bit adalah dari kiri kekanan dengan bit 1 menjadi most significant bit, jadi untuk 64 bit, bit 1 mempunyai nilai 263. Sebanyak 16 putaran enkripsi dilakukan menggunakan fungsi cipher $\mathrm{f}$ dan setiap putaran menggunakan kunci 48 bit yang berbeda dan dibuat berdasarkan kunci DES. Efeknya adalah setiap blok secara bergantian dienkripsi, masing-masing sebanyak 8 kali [7].

Standard Triple DES menggunakan algoritma DES dengan 3 kunci DES K1, K2 dan K3, enkripsi 3DES dilakukan sebagai berikut: (1). Enkripsi DES dengan kunci K1 dilakukan terhadap naskah asli. (2). Dekripsi DES dengan kunci K2 dilakukan terhadap hasil pertama. (3). Enkripsi DES dengan kunci K3 dilakukan terhadap hasil kedua.

Advanced Encryption Standard (AES) adalah teknik enkripsi yang dijadikan standard FIPS oleh NIST tahun 2001. AES dimaksudkan akan secara bertahap menggantikan DES sebagai standard enkripsi di Amerika Serikat untuk abad ke 21. Perbedaan utama antara teknik enkripsi AES dan teknik enkripsi DES adalah AES juga menggunakan substitusi (menggunakan S-boxes) secara langsung terhadap naskah, sedangkan substitusi S-box digunakan DES hanya dalam fungsi cipher $\mathrm{f}$ yang hasilnya kemudian dioperasikan terhadap naskah menggunakan exclusive or, jadi DES tidak menggunakan substitusi secara langsung terhadap naskah. AES juga menggunakan kunci enkripsi yang lebih besar yaitu 128 bit, 192 bit, atau 256 bit [7]. 
Tabel 1 Jumlah Putaran AES

\begin{tabular}{cccc}
\hline & Besar Kunci dalam Words & Besar Blok dalam Words & Jumlah Putaran \\
\hline AES-128 & 4 & 4 & 10 \\
AES-192 & 6 & 4 & 12 \\
AES-256 & 8 & 4 & 14 \\
\hline
\end{tabular}

Jumlah putaran tergantung pada besar kunci yang digunakan. Tabel 1 menunjukkan jumlah putaran untuk kunci sebesar 128 bit, 192 bit dan 256 bit. Kunci sebesar 128 bit, besar kunci adalah 4 word (setiap word mempunyai 32 bit), besar blok adalah 4 word, dan jumlah putaran adalah 10 [7].

Tabel 2 Perbandingan DES, 3DES dan AES

\begin{tabular}{|c|c|c|c|}
\hline & DES & 3DES & AES \\
\hline Panjang kunci & 56 bit & $\begin{array}{c}168 \text { bit (k1, k2 dan k3) } \\
112 \text { bit (k1 dan k2) }\end{array}$ & 128,192 , dan 256 bits \\
\hline Putaran & 16 & 48 & $\begin{array}{l}10-128 \text { bit, } \\
12-192 \text { bit, } \\
14-256 \text { bit }\end{array}$ \\
\hline Ukuran blok & 64 bit & 64 bit & 128 bit \\
\hline Jenis sandi & $\begin{array}{l}\text { Symmetric block } \\
\text { cipher }\end{array}$ & Symmetric block cipher & $\begin{array}{l}\text { Symmetric block } \\
\text { cipher }\end{array}$ \\
\hline Keamanan & Tidak cukup aman & Keamanan yang memadai & Keamanan luar biasa \\
\hline
\end{tabular}

Penelitian [8], membahas tentang studi banding algoritma enkripsi untuk keamanan informasi. Penelitian tersebut menyajikan studi rinci tentang Algoritma Enkripsi populer seperti DES, 3DES dan AES. Menurut penelitian tersebut dapat ditemukan bahwa algoritma AES merupakan algoritma yang sangat aman, Dapat dilihat pada tabel 2 perbandingan DES, 3DES dan AES.

Penelitian [5], membahas tentang algoritma keamanan pada VPN dan teknik enkripsinya. Algoritma yang digunakan pada penelitian tersebut yaitu AES, DES, 3DES, RC4, Blowfish dan IDEA menggunakan metode stream cipher dan protokol VPN IPSec. Penelitian [9], membahas tenang kinerja pada VPN menggunakan protokol PPTP, L2TP dan IPSec.

Penelitian [10], [11] dan [12], melakukan perbandingan antara VPN IPSec dengan VPN SSL. Penelitian [13] dan [14], melakukan perbandingan antara VPN IPSec dengan VPN PPTP. Penelitian [15] dan [16], mengimplementasikan kemananan jaringan komputer pada Virtual Private Network (VPN) menggunakan IPSec. Penelitian [17], membahas tentang kinerja terhadap topologi yang dikembangkan dengan teknologi MPLS dan Frame Relay untuk kerja VPN.

Penelitian yang dilakukan berfokus pada pengukuran transfer data pada proses download dan upload pada jaringan VPN IPSec dengan menerapkan algoritma DES, 3DES, AES 128, AES 192 dan AES 256 kemudian membandingkan hasil pengukurannya, yang mana pada penelitian-penelitian sebelumnya hanya membahas tentang keamanan algoritma dan protokol VPN.

\section{METODE PENELITIAN}

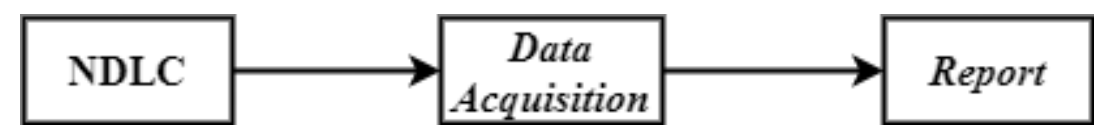

\section{Gambar 1 Alur penelitian}

Tahap alur penelitian yang pertama yaitu Network Development Life Cycle (NDLC) yang menjadi metodologi dari penelitian yang akan dilakukan. Metode yang digunakan dalam penelitian ini akan mengikuti metode Network Development Life Cycle (NDLC). Metode ini digunakan untuk 
merancang suatu jaringan yang teridi dari enam tahap yaitu Analysis, Design, Simulation Prototype, Implamentation, Monitoring, dan Management [18], [19], [20], namun pada penelitian ini akan memakai 3 tahap yaitu Analysis, Design, Implementation. Tahapan-tahapan dari metode NDLC tersebut dapat dijelaskan seperti berikut ini. Tahap selanjutnya Data Acquisition, yaitu pengambilan data dan tahap yang terakhir yaitu Reports atau mengalisa dari Data Acquisition yang menghasilkan suatu kesimpulan dari penelitian yang telah dilakukan.

\subsection{Analysis}

Tahap Analisa ini merupakan tahapan untuk melakukan analisis kebutuhan-kebutuhan dalam proses perancangan jaringan yang merupakan langkah atau tahapan dalam menentukan spesifikasi sistem yang menjelaskan kebutuhan baik dari segi perangkat keras ataupun perangkat lunak yang dibutuhkan dan skenario perancangan jaringan yang menggambarkan proses yang terjadi dalam peneitian yang dilakukan. Proses-proses tersebut yaitu kebutuhan hardware, kebutuhan software dan skenario perancangan.

\subsection{Design}

Langkah selanjutnya yang ditempuh adalah proses mendesain topologi jaringan untuk menggambarkan keterkaitan antar perangkat keras dan jaringan. Gambar rancangan yang dibuat dengan menggunakan tools cisco packet tracer.

\subsection{Implementation}

Tahap implementasi atau pembuatan jaringan. Setelah pada tahap pada tahap analysis dan design berjalan sesuai dengan apa yang telah dikerjakan, selanjutnya konfigurasi IP Address, konfigurasi IPSec dan Konfigurasi Frame Relay.

\section{HASIL DAN PEMBAHASAN}

Hasil yang diperoleh dari proses NDLC merupakan analisis kebutuhan hardware, kebutuhan software, skenario perancangan, topologi jaringan dan konfigurasi IP address, IPSec dan Frame Relay. Hasil dari proses Data Acquisition merupakan data-data dari percobaan transfer data download dan upload. Hasil dari proses Report merupakan analisa dari proses Data Acquisition berupa tabel dan grafik perbedaan dari setiap algoritma dan file yang diuji.

\subsection{Analysis}

\subsubsection{Kebutuhan Hardware}

Perangkat keras yang dibutuhkan dalam pembuatan simulasi jaringan komputer menggunakan VPN adalah sebagai berikut.

Tabel 3 Kebutuhan Perangkat Keras

\begin{tabular}{ll}
\hline \multicolumn{1}{c}{ Perangkat Keras } & \multicolumn{1}{c}{ Fungsi/Kegunaan } \\
\hline Router 1841 & $\begin{array}{l}\text { Meningkatkan kinerja VPN denganmodul akselerasi VPN opsional, sebuah } \\
\text { pencegahan intrusi sistem (IPS) dan fungsifirewall }\end{array}$ \\
\hline Switch & Sebagai konektor / penghubung pada suatu area terbatas \\
\hline PC & Antarmuka antara jaringan manusia dan jaringan komunikasi \\
\hline Server & $\begin{array}{l}\text { Menjalankan perangkat lunak administratif yangmengontrol akses terhadap } \\
\text { jaringan dan sumber daya yang terdapat di dalamnya }\end{array}$ \\
\hline Cloud & $\begin{array}{l}\text { Metafora dari internet,sebagaimana awan yang sering digambarkan di } \\
\text { diagram jaringan komputer }\end{array}$ \\
\hline
\end{tabular}

\subsubsection{Kebutuhan Software}

Perangkat lunak yang dibutuhkan dalam melakukan pembuatan simulasi jaringan komputer ini adalah Cisco Packet Tracer sebagai simulator untuk merangkai dan sekaligus mengkonfigurasi suatu jaringan.

\subsubsection{Skenario Perancangan}

a. Download file dari Server ke PC Client tanpa jaringan VPN 
b. Upload File dari PC Client ke Server tanpa jaringan VPN

c. Download file dari Server ke PC Client melalui jaringan VPN

d. Upload File dari PC Client ke Server melalui jaringan VPN

\subsection{Design}

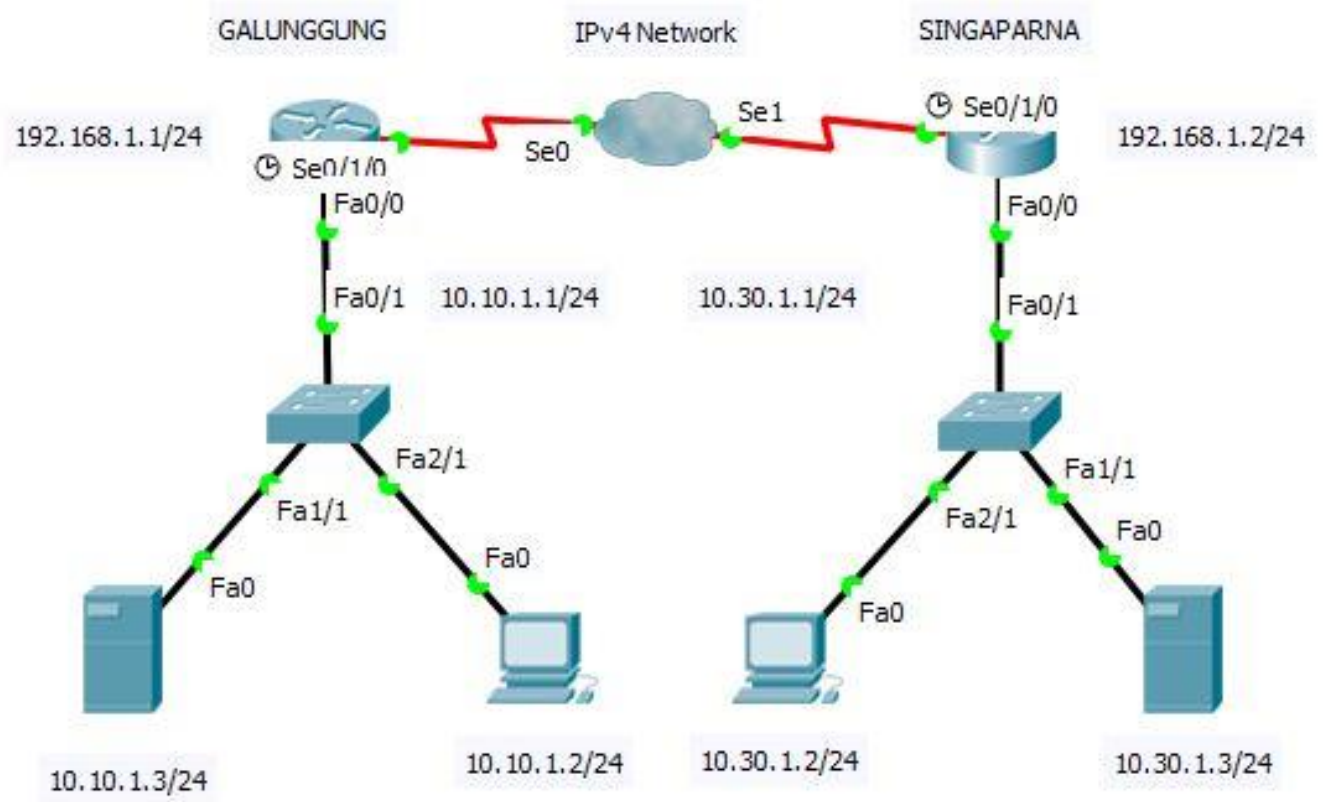

Gambar 2 Topologi jaringan

Gambar 2 menampilkan Topologi jaringan yang berfungsi untuk mengetahui bagaimana masing-masing perangkat dalam jaringan komputer dapat saling berkomunikasi satu sama lain. Topologi jaringan tersebut menggunakan 1 buah cloud, 2 buah router yang masing-masing routernya dibuat sebagai router server (Galunggung) dan router client (Singaparana). Setiap router memiliki 1 buah switch yang terhubung pada 1 buah server dan 1 buah PC.

\subsection{Implementation}

\subsubsection{Konfigurasi IP Address}

Konfigurasi IP address pada router, PC dan server sesuai pada gambar 2 topologi jaringan.

\subsubsection{Konfigurasi IPSec}

Terdapat 5 komponen dasar untuk melakukan konfigurasi Ipsec VPN. Komponen tersebut yaitu :

a. ACL

Memberikan access-list agar jaringan galunggung-singaparna bisa saling interkoneksi.

b. ISAKMP policy dan ISAKMP key

Konfigurasi VPN menggunakan isakmp policy untuk menentukan algoritma yang akan digunakan dan isakmp key untuk pertukaran kunci. Algoritma yang digunakan yaitu DES, 3DES, AES 128, AES 192, dan AES 256

c. IPsec transform-set

Konfigurasi ipsec dengan transform-set dan protocol security yang digunakan untuk membuat/merubah metode enkripsi algoritma hashing IPSec.

d. Crypto map

Konfigurasi nama dan nomor urut crypto map untuk membuat IPSec Policy.

e. Apply the crypto map

Memberikan crypto map diatas pada interface. 


\subsubsection{Frame relay}

Konfigurasi frame relay agar 2 router saling terhubung melalui cloud, dengan adanya frame relay dalam Wide Area Network, jaringan yang berjauhan akan dapat terkoneksi dengan kecepatan seperti jaringan jarak pendek.

\subsection{Data Acquisition}

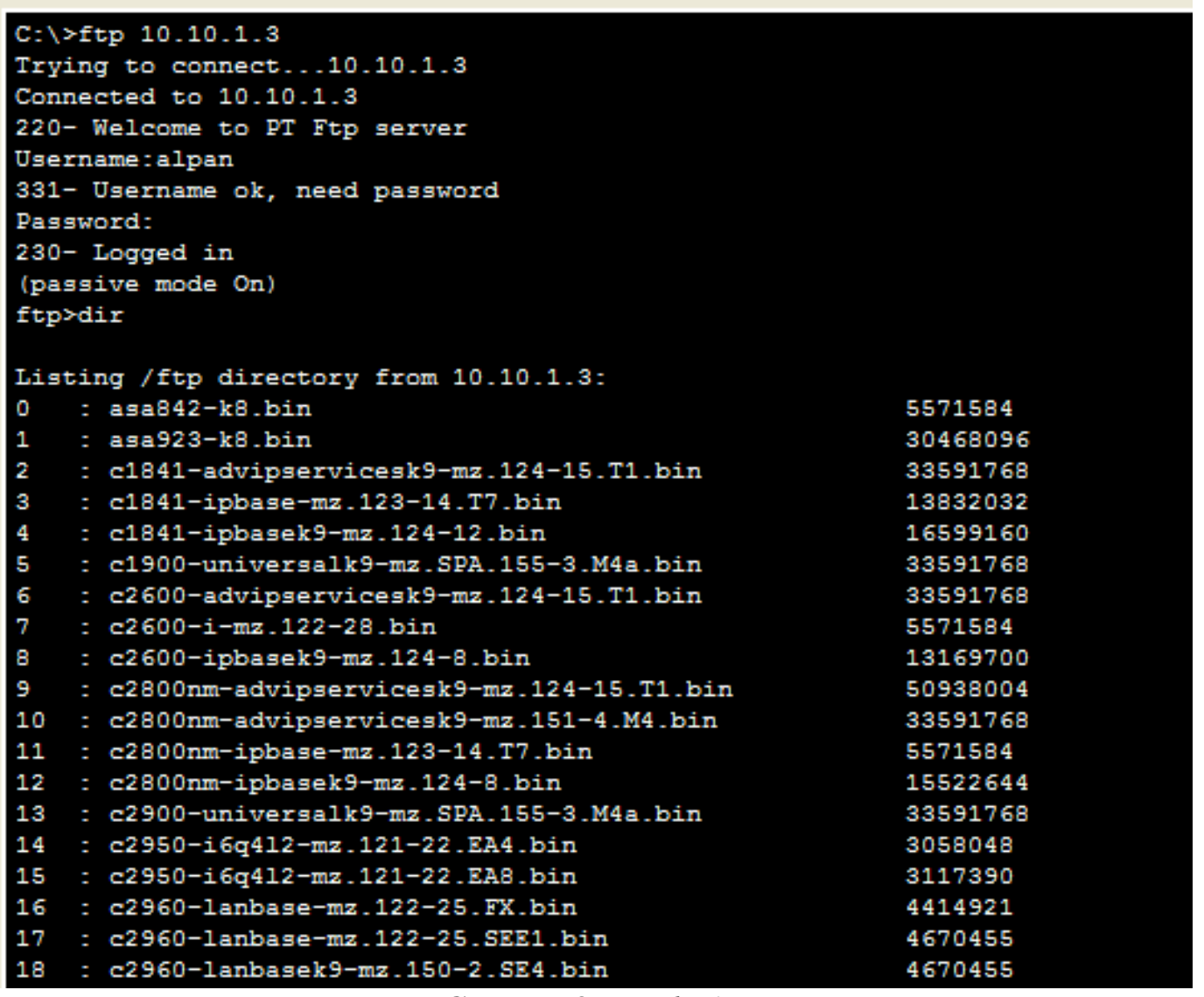

\section{Gambar 3 FTP login}

Gambar 3 menampilkan client singaparna mencoba masuk ke 10.10.1.3 (server galunggung) dengan menggunakan username : alpan dan password : 12345 atau dapat masuk mengunakan username dan password default yakni username : cisco dan password : cisco. Server galunggung memiliki beberapa file dengan jenis file bin.

Penelitian ini hanya menggunakan 3 file yang ada pada server galunggung yaitu file ke-0 asa842k8.bin (5571584 bytes), ke-2 c1841-advipservicesk9-mz.124-15.T1.bin (33591768 bytes), dan ke-4 c1841-ipbasek9-mz.124-12.bin (16599160 bytes). Ketiga file tersebut dipilih berdasarkan ukuran file yang berbeda jauh. Penelitian ini dilakukan dengan setting bandwidth $100 \mathrm{MB} / \mathrm{s}$. Proses download file dengan melakukan perintah get "nama file" dan upload file dengan perintah put "nama file".

\section{a. Tanpa VPN}

Tabel 4 Hasil Download Tanpa VPN

\begin{tabular}{cccccc}
\hline \multicolumn{2}{c}{ File ke-0 } & \multicolumn{2}{c}{ File ke-2 } & \multicolumn{2}{c}{ File ke-4 } \\
\hline $\boldsymbol{s}$ & bytes $/ \boldsymbol{s}$ & $\boldsymbol{s}$ & bytes $/ \boldsymbol{s}$ & $\boldsymbol{s}$ & bytes/s \\
\hline 9,091 & 140426 & 53,055 & 66478 & 30,144 & 123217 \\
\hline 8,911 & 143263 & 54,298 & 64836 & 30,664 & 121127 \\
\hline
\end{tabular}

Permana, Perbandingan Algoritma Pada Teknologi Virtual Private Network (VPN) IPSec Terhadap Kecepatan Transfer Data 


\begin{tabular}{llllll}
\hline 8,866 & 143990 & 56,108 & 62860 & 30,697 & 120997 \\
\hline 8,906 & 143343 & 56,173 & 62788 & 30,721 & 120902 \\
\hline 8,853 & 144201 & 61,147 & 57680 & 30,531 & 121655 \\
\hline 8,840 & 144413 & 61,293 & 57543 & 30,816 & 120530 \\
\hline 8,876 & 143827 & 59,702 & 59076 & 31,142 & 119268 \\
\hline 9,091 & 140426 & 56,645 & 62264 & 30,495 & 121798 \\
\hline 8,825 & 144659 & 69,152 & 59625 & 30,816 & 120530 \\
\hline 8,835 & 144495 & 58,992 & 59787 & 30,098 & 123405 \\
\hline $\mathbf{8 , 9 0 9}$ & $\mathbf{1 4 3 3 0 4}$ & $\mathbf{5 8 , 6 5 7}$ & $\mathbf{6 1 2 9 4}$ & $\mathbf{3 0 , 6 1 2}$ & $\mathbf{1 2 1 3 4 3}$ \\
\hline
\end{tabular}

Tabel 4 menunjukan 10 hasil percobaan download pada file ke-0 dengan rata-rata waktu 8,909 seconds (143304 bytes/seconds), file ke-2 dengan rata-rata waktu 58,657 seconds (61294 bytes/seconds), dan file ke-4 dengan rata-rata waktu 30,612 seconds (121343 bytes/seconds).

Tabel 5 Hasil Upload Tanpa VPN

\begin{tabular}{cccccc}
\hline \multicolumn{2}{c}{ File ke-0 } & \multicolumn{2}{c}{ File ke-2 } & \multicolumn{2}{c}{ File ke-4 } \\
\hline $\boldsymbol{s}$ & bytes $\boldsymbol{s}$ & $\boldsymbol{s}$ & bytes $/ \boldsymbol{s}$ & $\boldsymbol{s}$ & bytes $/ \mathbf{s}$ \\
\hline 9,093 & 140395 & 62,219 & 56686 & 32,137 & 115575 \\
\hline 8,975 & 142241 & 58,576 & 60212 & 30,021 & 123721 \\
\hline 9,199 & 138777 & 62,211 & 56694 & 30,806 & 120569 \\
\hline 9,126 & 139887 & 62,992 & 55991 & 29,733 & 124920 \\
\hline 9,560 & 133537 & 59,688 & 59090 & 29,810 & 124597 \\
\hline 8,906 & 143343 & 62,493 & 56438 & 30,671 & 121100 \\
\hline 9,055 & 140984 & 63,913 & 55184 & 30,989 & 119857 \\
\hline 9,070 & 140751 & 63,173 & 55830 & 31,180 & 119123 \\
\hline 9,318 & 137005 & 64,030 & 55083 & 31,277 & 118753 \\
\hline 9,118 & 140010 & 63,023 & 55963 & 30,336 & 122437 \\
\hline $\mathbf{9 , 1 4 2}$ & $\mathbf{1 3 9 6 9 3}$ & $\mathbf{6 2 , 2 3 2}$ & $\mathbf{5 6 7 1 7}$ & $\mathbf{3 0 , 6 9 6}$ & $\mathbf{1 2 1 0 6 5}$ \\
\hline
\end{tabular}

Tabel 5 menunjukan 10 hasil percobaan upload pada file ke-0 dengan rata-rata waktu 9,142 seconds (139693 bytes/seconds), file ke-2 dengan rata-rata waktu 62,232 seconds (56717 bytes/seconds), dan file ke-4 dengan rata-rata waktu 30,696 seconds (121065 bytes/seconds).

\section{b. DES}

Tabel 6 Download Menggunakan DES

\begin{tabular}{cccccc}
\hline \multicolumn{2}{c}{ File ke-0 } & \multicolumn{2}{c}{ File ke-2 } & \multicolumn{2}{c}{ File ke-4 } \\
\hline $\boldsymbol{s}$ & bytes $/ \boldsymbol{s}$ & $\boldsymbol{s}$ & bytes $/ \boldsymbol{s}$ & $\boldsymbol{s}$ & bytes $/ \mathbf{s}$ \\
\hline 12,178 & 104829 & 71,677 & 49206 & 34,308 & 108262 \\
\hline 11,872 & 107531 & 73,928 & 47708 & 36,15 & 102745 \\
\hline
\end{tabular}




\begin{tabular}{llllll}
\hline 11,738 & 108759 & 73,123 & 48233 & 35,335 & 105115 \\
\hline 11,858 & 107658 & 73,537 & 47962 & 36,548 & 101626 \\
\hline 11,920 & 107098 & 74,367 & 47426 & 35,663 & 104148 \\
\hline 11,620 & 109863 & 74,043 & 47634 & 36,575 & 101551 \\
\hline 11,630 & 109759 & 73,952 & 47693 & 35,89 & 103490 \\
\hline 11,503 & 110981 & 73,666 & 47878 & 36,128 & 102808 \\
\hline 12,115 & 105374 & 73,639 & 47895 & 36,13 & 102802 \\
\hline 11,709 & 109028 & 73,438 & 48026 & 36,04 & 103059 \\
\hline $\mathbf{1 1 , 8 1 4}$ & $\mathbf{1 0 8 0 8 8}$ & $\mathbf{7 3 , 5 3 7}$ & $\mathbf{4 7 9 6 6}$ & $\mathbf{3 5 , 8 7 7}$ & $\mathbf{1 0 3 5 6 1}$ \\
\hline
\end{tabular}

Tabel 6 menunjukan 10 hasil percobaan download pada file ke-0 dengan rata-rata waktu 11,814 seconds (108088 bytes/seconds), file ke-2 dengan rata-rata waktu 73,537 seconds (47966 bytes/seconds), dan file ke-4 dengan rata-rata waktu 35,877 seconds (103561 bytes/seconds).

Tabel 7 Upload Menggunakan DES

\begin{tabular}{cccccc}
\hline \multicolumn{2}{c}{ File ke-0 } & \multicolumn{2}{c}{ File ke-2 } & \multicolumn{2}{c}{ File ke-4 } \\
\hline $\boldsymbol{s}$ & bytes $/ \boldsymbol{s}$ & $\boldsymbol{s}$ & bytes $/ \boldsymbol{s}$ & $\boldsymbol{s}$ & bytes/s \\
\hline 10,359 & 123237 & 72,324 & 48766 & 35,058 & 105946 \\
\hline 12,432 & 102687 & 75,799 & 46530 & 37,413 & 99277 \\
\hline 11,998 & 106402 & 74,113 & 47589 & 36,953 & 100513 \\
\hline 12,685 & 100639 & 74,34 & 47444 & 37,011 & 100355 \\
\hline 12,223 & 104443 & 74,861 & 47113 & 36,892 & 100679 \\
\hline 12,430 & 102704 & 74,158 & 47560 & 36,641 & 101368 \\
\hline 12,546 & 101754 & 74,81 & 47146 & 36,814 & 100892 \\
\hline 12,274 & 104009 & 74,469 & 47361 & 36,605 & 101468 \\
\hline 12,607 & 101262 & 74,495 & 47345 & 36,852 & 100788 \\
\hline 12,532 & 101868 & 74,801 & 47151 & 37,264 & 99674 \\
\hline $\mathbf{1 2 , 2 0 9}$ & $\mathbf{1 0 4 9 0 1}$ & $\mathbf{7 4 , 4 1 7}$ & $\mathbf{4 7 4 0 1}$ & $\mathbf{3 6 , 7 5 0}$ & $\mathbf{1 0 1 0 9 6}$ \\
\hline
\end{tabular}

Tabel 7 menunjukan 10 hasil percobaan upload pada file ke-0 dengan rata-rata waktu 12,209 seconds (104901 bytes/seconds), file ke-2 dengan rata-rata waktu 74,417 seconds (47401 bytes/seconds), dan file ke-4 dengan rata-rata waktu 36,750 seconds (101096 bytes/seconds).

\section{c. 3DES}

Tabel 8 Download Menggunakan 3DES

\begin{tabular}{cccccc}
\hline \multicolumn{2}{c}{ File ke-0 } & \multicolumn{2}{c}{ File ke-2 } & \multicolumn{2}{c}{ File ke-4 } \\
\hline $\boldsymbol{s}$ & bytes $/ \boldsymbol{s}$ & $\boldsymbol{s}$ & bytes $/ \boldsymbol{s}$ & $\boldsymbol{s}$ & bytes $/ \mathbf{s}$ \\
\hline 10,250 & 124547 & 70,198 & 50243 & 31,906 & 116412 \\
\hline 10,091 & 126510 & 63,934 & 55166 & 34,275 & 108366 \\
\hline
\end{tabular}




\begin{tabular}{cccccc}
\hline 10,071 & 126761 & 63,934 & 55241 & 35,051 & 105967 \\
\hline 9,938 & 128458 & 62,205 & 56699 & 34,573 & 107432 \\
\hline 10,178 & 125429 & 62,206 & 56698 & 32,026 & 115976 \\
\hline 10,258 & 124450 & 66,613 & 52947 & 32,641 & 113791 \\
\hline 10,060 & 126900 & 70,246 & 50209 & 32,032 & 115954 \\
\hline 9,966 & 128097 & 71,938 & 49028 & 31,180 & 119123 \\
\hline 10,055 & 126963 & 71,336 & 49442 & 32,207 & 115324 \\
\hline 10,422 & 122492 & 71,773 & 49140 & 35,829 & 103666 \\
\hline $\mathbf{1 0 , 1 2 9}$ & $\mathbf{1 2 6 0 6 1}$ & $\mathbf{6 7 , 4 3 8}$ & $\mathbf{5 2 4 8 1}$ & $\mathbf{3 3 , 1 7 2}$ & $\mathbf{1 1 2 2 0 1}$ \\
\hline
\end{tabular}

Tabel 8 menunjukan 10 hasil percobaan download pada file ke-0 dengan rata-rata waktu 10,129 seconds (126061 bytes/seconds), file ke-2 dengan rata-rata waktu 67,438 seconds (52481 bytes/seconds), dan file ke-4 dengan rata-rata waktu 33,172 seconds (112201 bytes/seconds).

Tabel 9 Upoload Menggunakan 3DES

\begin{tabular}{cccccc}
\hline \multicolumn{2}{c}{ File ke-0 } & \multicolumn{2}{c}{ File ke-2 } & \multicolumn{2}{c}{ File ke-4 } \\
\hline $\boldsymbol{s}$ & bytes $/ \boldsymbol{s}$ & $\boldsymbol{s}$ & bytes $/ \boldsymbol{s}$ & $\boldsymbol{s}$ & bytes $/ \mathbf{s}$ \\
\hline 10,351 & 123332 & 72,429 & 48695 & 33,864 & 109681 \\
\hline 9,992 & 127763 & 71,192 & 49542 & 35,133 & 105719 \\
\hline 9,985 & 127853 & 72,125 & 48901 & 31,276 & 118757 \\
\hline 10,085 & 126585 & 72,621 & 48567 & 35,669 & 104131 \\
\hline 9,989 & 127802 & 69,893 & 50462 & 35,807 & 103729 \\
\hline 10,435 & 122339 & 65,608 & 53758 & 34,266 & 108394 \\
\hline 10,040 & 127153 & 62,939 & 56038 & 35,791 & 103776 \\
\hline 10,120 & 126147 & 63,190 & 55815 & 31,980 & 116143 \\
\hline 10,035 & 127216 & 72,451 & 55815 & 30,837 & 120448 \\
\hline 10,601 & 120424 & 72,438 & 48689 & 30,121 & 123311 \\
\hline $\mathbf{1 0 , 1 6 3}$ & $\mathbf{1 2 5 6 6 1}$ & $\mathbf{6 9 , 4 8 9}$ & $\mathbf{5 1 6 2 8}$ & $\mathbf{3 3 , 4 7 4}$ & $\mathbf{1 1 1 4 0 9}$ \\
\hline
\end{tabular}

Tabel 9 menunjukan 10 hasil percobaan upload pada file ke-0 dengan rata-rata waktu 10,163 seconds (125661 bytes/seconds), file ke-2 dengan rata-rata waktu 69,489 seconds (51628 bytes/seconds), dan file ke-4 dengan rata-rata waktu 33,474 seconds (111409 bytes/seconds).

\section{d. AES 128}

Tabel 10 Download Menggunakan AES 128

File ke-0

\begin{tabular}{cccccc}
\hline $\boldsymbol{s}$ & bytes/s & $\boldsymbol{s}$ & bytes/s & $\boldsymbol{s}$ & bytes/s \\
\hline 12,257 & 104154 & 74,078 & 47611 & 35,880 & 103518 \\
\hline 11,838 & 107840 & 73,766 & 47813 & 36,201 & 102600 \\
\hline
\end{tabular}




\begin{tabular}{llllll}
\hline 11,600 & 110053 & 73,196 & 48185 & 33,683 & 110271 \\
\hline 11,850 & 107731 & 73,232 & 48161 & 36,240 & 102490 \\
\hline 11,849 & 107740 & 74,304 & 47467 & 35,880 & 103518 \\
\hline 11,710 & 109019 & 73,032 & 48293 & 36,634 & 101388 \\
\hline 11,730 & 108833 & 72,746 & 48483 & 36,342 & 102202 \\
\hline 11,522 & 110798 & 73,289 & 48124 & 36,237 & 102499 \\
\hline 11,956 & 106776 & 73,505 & 47983 & 36,133 & 102794 \\
\hline 11,683 & 109271 & 73,130 & 48229 & 35,793 & 103770 \\
\hline $\mathbf{1 1 , 8 0 0}$ & $\mathbf{1 0 8 2 2 2}$ & $\mathbf{7 3 , 4 2 8}$ & $\mathbf{4 8 0 3 5}$ & $\mathbf{3 5 , 9 0 2}$ & $\mathbf{1 0 3 5 0 5}$ \\
\hline
\end{tabular}

Tabel 10 menunjukan 10 hasil percobaan download pada file ke-0 dengan rata-rata waktu 11,800 seconds (108222 bytes/seconds), file ke-2 dengan rata-rata waktu 73,428 seconds (48035 bytes/seconds), dan file ke-4 dengan rata-rata waktu 35,902 seconds (103505 bytes/seconds).

Tabel 11 Upload Menggunakan AES 128

\begin{tabular}{cccccc}
\hline \multicolumn{2}{c}{ File ke-0 } & \multicolumn{2}{c}{ File ke-2 } & \multicolumn{2}{c}{ File ke-4 } \\
\hline $\boldsymbol{s}$ & bytes $/ \boldsymbol{s}$ & $\boldsymbol{s}$ & bytes $\mathbf{s}$ & $\boldsymbol{s}$ & bytes/s \\
\hline 12,353 & 103344 & 71,947 & 49022 & 34,842 & 106602 \\
\hline 10,418 & 122539 & 74,525 & 47326 & 36,258 & 102439 \\
\hline 11,744 & 108703 & 73,156 & 48211 & 37,387 & 99346 \\
\hline 12,650 & 100918 & 74,501 & 47341 & 37,187 & 99880 \\
\hline 12,053 & 105916 & 74,985 & 47036 & 36,795 & 100944 \\
\hline 12,666 & 100790 & 74,897 & 47091 & 36,350 & 102180 \\
\hline 12,771 & 99962 & 73,435 & 48028 & 37,132 & 100028 \\
\hline 12,368 & 103219 & 75,213 & 46893 & 36,619 & 101429 \\
\hline 12,277 & 103984 & 74,777 & 47166 & 37,105 & 100101 \\
\hline 12,420 & 102787 & 74,653 & 47245 & 37,538 & 98946 \\
\hline $\mathbf{1 2 , 1 7 2}$ & $\mathbf{1 0 5 2 1 6}$ & $\mathbf{7 4 , 2 0 9}$ & $\mathbf{4 7 5 3 6}$ & $\mathbf{3 6 , 7 2 1}$ & $\mathbf{1 0 1 1 9 0}$ \\
\hline
\end{tabular}

Tabel 11 menunjukan 10 hasil percobaan upload pada file ke-0 dengan rata-rata waktu 12,172 seconds (74,209 bytes/seconds), file ke-2 dengan rata-rata waktu 74,209 seconds (47536 bytes/seconds), dan file ke-4 dengan rata-rata waktu 36,721 seconds (101190 bytes/seconds).

\section{e. AES 192}

Tabel 12 Download Menggunakan AES 192

\begin{tabular}{cccccc}
\hline \multicolumn{2}{c}{ File ke-0 } & \multicolumn{2}{c}{ File ke-2 } & \multicolumn{2}{c}{ File ke-4 } \\
\hline $\boldsymbol{s}$ & bytes $/ \boldsymbol{s}$ & $\boldsymbol{s}$ & bytes $/ \boldsymbol{s}$ & $\boldsymbol{s}$ & bytes $/ \mathbf{s}$ \\
\hline 10,318 & 123727 & 72,673 & 48532 & 36,780 & 100985 \\
\hline 12,212 & 104537 & 75,378 & 46790 & 36,080 & 102945 \\
\hline
\end{tabular}




\begin{tabular}{llllll}
\hline 12,266 & 104077 & 74,242 & 47506 & 36,212 & 102569 \\
\hline 12,524 & 101933 & 75,510 & 46709 & 35,704 & 104029 \\
\hline 12,173 & 104872 & 76,496 & 46106 & 36,411 & 102009 \\
\hline 12,160 & 104984 & 74,614 & 47269 & 36,391 & 102065 \\
\hline 12,067 & 105794 & 74,786 & 47161 & 35,942 & 103340 \\
\hline 12,180 & 104812 & 75,830 & 46511 & 36,163 & 102708 \\
\hline 12,117 & 105357 & 75,074 & 46980 & 36,005 & 103159 \\
\hline 12,062 & 105837 & 75,583 & 46663 & 36,685 & 101247 \\
\hline $\mathbf{1 2 , 0 0 8}$ & $\mathbf{1 0 6 5 9 3}$ & $\mathbf{7 5 , 0 1 9}$ & $\mathbf{4 7 0 2 3}$ & $\mathbf{3 6 , 2 3 7}$ & $\mathbf{1 0 2 5 0 6}$ \\
\hline
\end{tabular}

Tabel 12 menunjukan 10 hasil percobaan download pada file ke-0 dengan rata-rata waktu 12,008 seconds (106593 bytes/seconds), file ke-2 dengan rata-rata waktu 75,019 seconds (47023 bytes/seconds), dan file ke-4 dengan rata-rata waktu 36,237 seconds (102506 bytes/seconds).

Tabel 13 Upload Menggunakan AES 192

\begin{tabular}{cccccc}
\hline \multicolumn{2}{c}{ File ke-0 } & \multicolumn{2}{c}{ File ke-2 } & \multicolumn{2}{c}{ File ke-4 } \\
\hline $\boldsymbol{s}$ & bytes $/ \boldsymbol{s}$ & $\boldsymbol{s}$ & bytes $\mathbf{s}$ & $\boldsymbol{s}$ & bytes/s \\
\hline 10,551 & 120994 & 73,047 & 48283 & 35,102 & 105813 \\
\hline 12,652 & 100902 & 77,983 & 45227 & 37,873 & 98071 \\
\hline 12,631 & 101070 & 77,174 & 45701 & 37,954 & 97862 \\
\hline 13,042 & 97885 & 76,721 & 45971 & 38,289 & 97005 \\
\hline 12,435 & 102663 & 76,102 & 46345 & 37,449 & 99181 \\
\hline 12,678 & 100695 & 76,101 & 46346 & 37,819 & 98211 \\
\hline 12,713 & 100418 & 75,622 & 46639 & 37,151 & 99977 \\
\hline 12,166 & 104933 & 77,309 & 45622 & 37,184 & 99888 \\
\hline 12,571 & 101552 & 76,439 & 46141 & 37,638 & 98683 \\
\hline 12,792 & 99798 & 76,953 & 45833 & 37,523 & 98986 \\
\hline $\mathbf{1 2 , 4 2 3}$ & $\mathbf{1 0 3 0 9 1}$ & $\mathbf{7 6 , 3 4 5}$ & $\mathbf{4 6 2 1 1}$ & $\mathbf{3 7 , 3 9 8}$ & $\mathbf{9 9 3 6 8}$ \\
\hline
\end{tabular}

Tabel 13 menunjukan 10 hasil percobaan upload pada file ke-0 dengan rata-rata waktu 12,423 seconds (103091 bytes/seconds), file ke-2 dengan rata-rata waktu 76,345 seconds (46211 bytes/seconds), dan file ke-4 dengan rata-rata waktu 37,398 seconds ( 99368 bytes/seconds).

\section{f. AES 256}

Tabel 14 Download Menggunakan AES 256

\begin{tabular}{cccccc}
\hline \multicolumn{2}{c}{ File ke-0 } & \multicolumn{2}{c}{ File ke-2 } & \multicolumn{2}{c}{ File ke-4 } \\
\hline $\boldsymbol{s}$ & bytes $/ \boldsymbol{s}$ & $\boldsymbol{s}$ & bytes $/ \boldsymbol{s}$ & $\boldsymbol{s}$ & bytes $/ \mathbf{s}$ \\
\hline 11,554 & 110491 & 72,692 & 48519 & 30,616 & 121317 \\
\hline 10,864 & 117508 & 74,761 & 47176 & 36,672 & 101283 \\
\hline
\end{tabular}




\begin{tabular}{cccccc}
\hline 12,253 & 104188 & 74,457 & 47369 & 37,053 & 100241 \\
\hline 12,460 & 102457 & 75,225 & 46885 & 36,381 & 102093 \\
\hline 12,162 & 104967 & 76,576 & 46058 & 37,681 & 98571 \\
\hline 12,106 & 105453 & 74,631 & 47259 & 36,795 & 100944 \\
\hline 12,171 & 104890 & 74,679 & 47228 & 36,341 & 102205 \\
\hline 12,145 & 105114 & 75,352 & 46806 & 36,294 & 102338 \\
\hline 12,181 & 104803 & 75,023 & 47012 & 36,782 & 100980 \\
\hline 12,055 & 105899 & $\mathbf{7 5 , 2 6 8}$ & 46859 & 36,936 & 100559 \\
\hline $\mathbf{1 1 , 9 9 5}$ & $\mathbf{1 0 6 5 7 7}$ & $\mathbf{7 4 , 8 6 6}$ & $\mathbf{4 7 1 1 7}$ & $\mathbf{3 6 , 1 5 5}$ & $\mathbf{1 0 3 0 5 3}$ \\
\hline
\end{tabular}

Tabel 14 menunjukan 10 hasil percobaan download pada file ke-0 dengan rata-rata waktu 11,995 seconds (106577 bytes/seconds), file ke-2 dengan rata-rata waktu 74,866 seconds (47117 bytes/seconds), dan file ke-4 dengan rata-rata waktu 36,155 seconds (103053 bytes/seconds).

Tabel 15 upload menggunakan AES 256

\begin{tabular}{cccccc}
\hline \multicolumn{2}{c}{ File ke-0 } & \multicolumn{2}{c}{ File ke-2 } & \multicolumn{2}{c}{ File ke-4 } \\
\hline $\boldsymbol{s}$ & bytes $/ \boldsymbol{s}$ & $\boldsymbol{s}$ & bytes $/ \boldsymbol{s}$ & $\boldsymbol{s}$ & bytes $/ \mathbf{s}$ \\
\hline 12,752 & 100111 & 72,743 & 48485 & 34,772 & 106817 \\
\hline 10,250 & 124547 & 76,799 & 45925 & 37,341 & 99468 \\
\hline 12,442 & 102605 & 76,425 & 46149 & 38,294 & 96993 \\
\hline 12,983 & 98329 & 76,726 & 45968 & 38,098 & 97492 \\
\hline 12,199 & 104649 & 76,077 & 46360 & 37,776 & 98323 \\
\hline 12,486 & 102243 & 75,840 & 46505 & 37,293 & 99596 \\
\hline 12,626 & 101110 & 75,725 & 46576 & 37,657 & 98633 \\
\hline 12,089 & 105601 & 77,275 & 45642 & 37,519 & 98996 \\
\hline 13,012 & 98110 & 76,706 & 45980 & 37,309 & 99553 \\
\hline 12,535 & 101844 & 77,209 & 45681 & 36,721 & 101148 \\
\hline $\mathbf{1 2 , 3 3 7}$ & $\mathbf{1 0 3 9 1 5}$ & $\mathbf{7 6 , 1 5 3}$ & $\mathbf{4 6 3 2 7}$ & $\mathbf{3 7 , 2 7 8}$ & $\mathbf{9 9 7 0 2}$ \\
\hline
\end{tabular}

Tabel 15 menunjukan 10 hasil percobaan upload pada file ke-0 dengan rata-rata waktu 12,337 seconds (103915 bytes/seconds), file ke-2 dengan rata-rata waktu 76,153 seconds (46327 bytes/seconds), dan file ke-4 dengan rata-rata waktu 37,278 seconds ( 99702 bytes/seconds).

\subsection{Report}

Tabel 16 Hasil Download

\begin{tabular}{lcccccc}
\hline & \multicolumn{2}{c}{ File ke-0 } & \multicolumn{2}{c}{ File ke-2 } & \multicolumn{2}{c}{ File ke-4 } \\
\cline { 2 - 7 } & $\boldsymbol{s}$ & rasio & $\boldsymbol{S}$ & rasio & $\boldsymbol{s}$ & rasio \\
\hline Tanpa VPN & 8,909 & & 58,657 & & 30,612 & \\
\hline DES & 11,814 & $32,60 \%$ & 73,537 & $25,37 \%$ & 35,877 & $17,20 \%$ \\
\hline 3DES & 10,129 & $13,69 \%$ & 67,438 & $14,97 \%$ & 33,172 & $8,36 \%$ \\
\hline
\end{tabular}

Permana, Perbandingan Algoritma Pada Teknologi Virtual Private Network (VPN) IPSec Terhadap Kecepatan Transfer Data 


\begin{tabular}{lllllll}
\hline AES 128 & 11,800 & $32,44 \%$ & 73,428 & $25,18 \%$ & 35,902 & $17,28 \%$ \\
\hline AES 192 & 12,008 & $34,78 \%$ & 75,019 & $27,89 \%$ & 36,237 & $18,37 \%$ \\
\hline AES 256 & 11,995 & $34,63 \%$ & 74,866 & $27,64 \%$ & 36,155 & $18,11 \%$ \\
\hline
\end{tabular}

Tabel 17 Hasil Upload

\begin{tabular}{lcccccc}
\hline & \multicolumn{2}{c}{ File ke-0 } & \multicolumn{2}{c}{ File ke-2 } & \multicolumn{2}{c}{ File ke-4 } \\
\cline { 2 - 7 } & $\boldsymbol{s}$ & rasio & $\boldsymbol{S}$ & rasio & $\boldsymbol{s}$ & rasio \\
\hline Tanpa VPN & 9,142 & & 62,232 & & 30,696 & \\
\hline DES & 12,209 & $33,54 \%$ & 74,417 & $19,58 \%$ & 36,750 & $19,72 \%$ \\
\hline 3DES & 10,163 & $11,17 \%$ & 69,489 & $11,66 \%$ & 33,474 & $9,05 \%$ \\
\hline AES 128 & 12,172 & $33,14 \%$ & 74,209 & $19,25 \%$ & 36,721 & $19,63 \%$ \\
\hline AES 192 & 12,423 & $35,89 \%$ & 76,345 & $22,68 \%$ & 37,398 & $21,83 \%$ \\
\hline AES 256 & 12,337 & $34,95 \%$ & 76,153 & $22,37 \%$ & 37,278 & $21,44 \%$ \\
\hline
\end{tabular}

Tabel 16 dan tabel 17 menunjukan hasil dari rata-rata waktu setiap file dan algoritma yang diuji, yang mana algoritma yang mempunyai waktu paling sedikit merupakan algoritma yang paling cepat dalam proses transfer data dengan rasio yang lebih rendah.

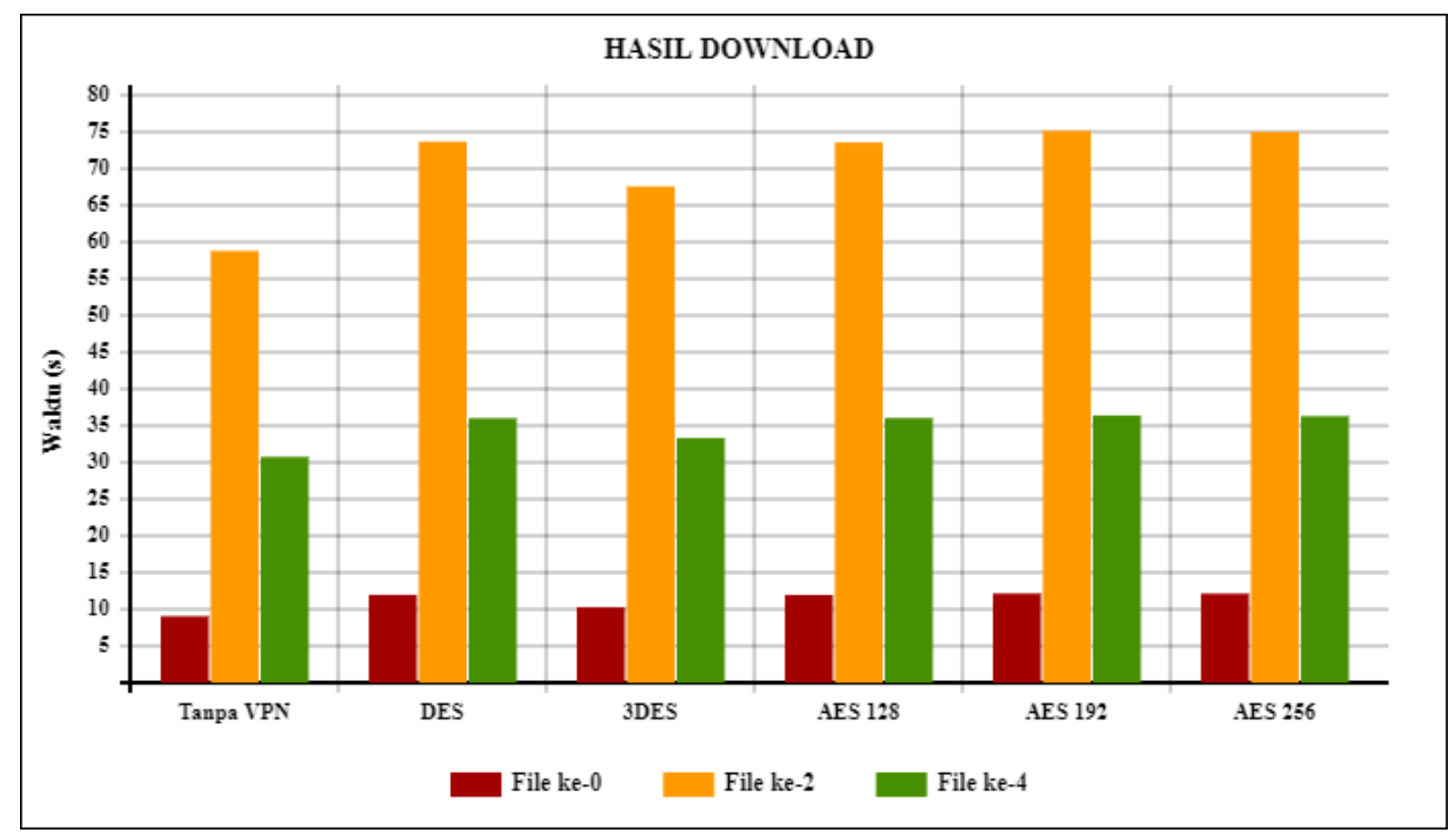

Gambar 4 Chart Hasil Download 


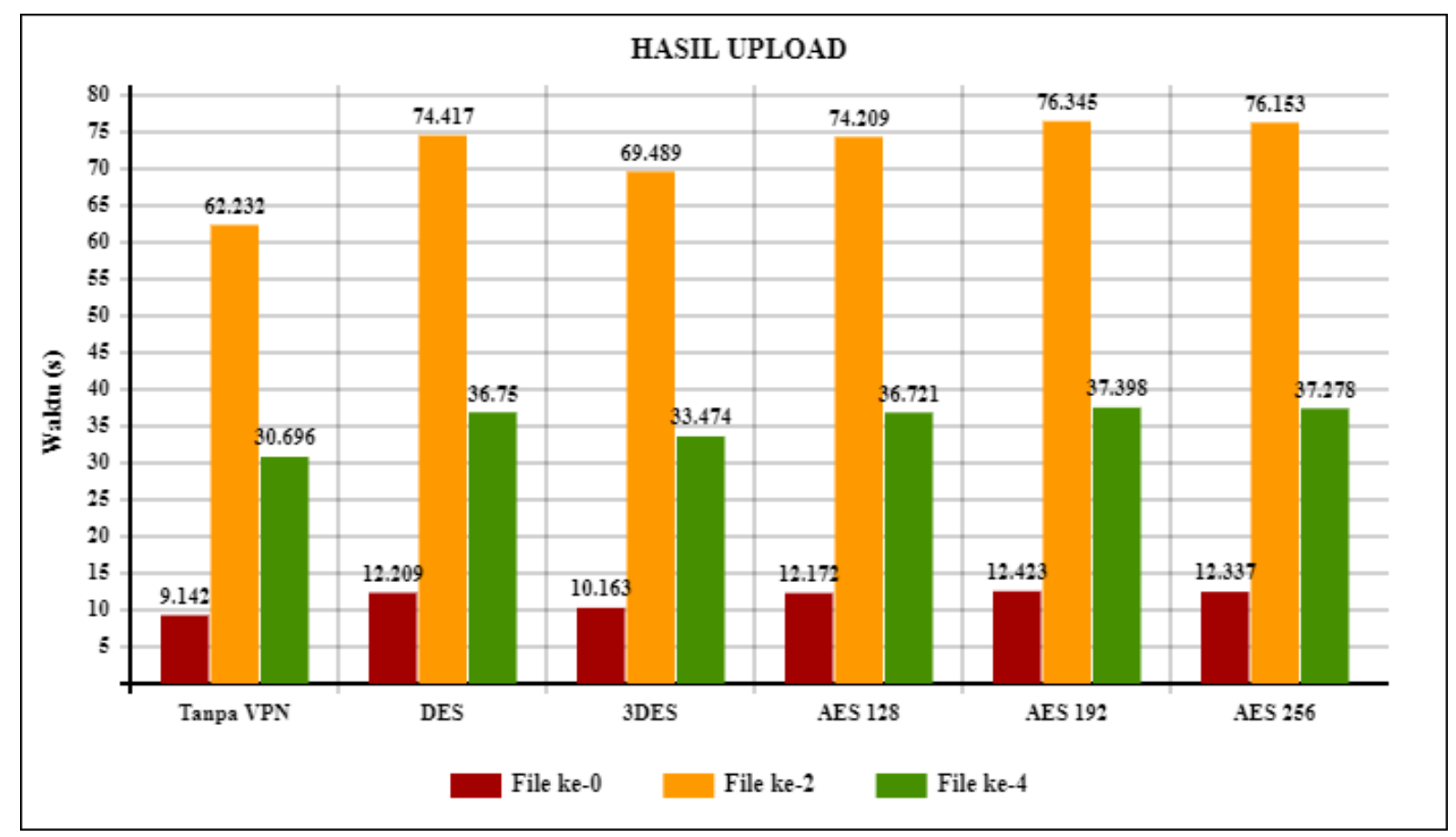

Gambar 5 Chart hasil upload

Gambar 4 dan 5 menampilkan variasi kecepatan transfer data yang menunjukan bahwa tingkatan yang paling rendah merupakan algoritma yang paling cepat dan tingkatan yang paling tinggi merupakan algoritma yang paling lambat. Berdasarkan gambar tersebut dapat dintentukan urutan algoritma dari yang tercepat dalam proses transfer data, yang pertama yaitu 3DES, kedua AES 128, ketiga DES, keempat AES 192 dan kelima AES 256.

\section{KESIMPULAN}

Kesimpulan yang dapat diambil dari penelitian ini yaitu algoritma yang paling optimal dalam melakukan transfer data pada VPN adalah 3DES. Algoritma tersebut unggul pada file ke-0 dengan kecepatan 10,129 seconds serta dengan rasio 13,69\% lebih lambat, file ke-2 dengan kecepatan 67,438 seconds serta dengan rasio 14,97\% lebih lambat dan pada file ke-4 dengan kecepatan 33,172 seconds serta dengan rasio 8,36\% lebih lambat pada proses download. Sedangkan pada proses upload 3DES juga unggul pada file ke-0 dengan kecepatan 10,163 seconds serta dengan rasio 11,17\% lebih lambat, file ke-2 dengan kecepatan 69,489 seconds serta dengan rasio 11,66\% lebih lambat dan pada file ke-4 dengan kecepatan 33,474 seconds serta dengan rasio 9,05\% lebih lambat.

Algoritma yang paling lambat dalam melakukan transfer data pada VPN adalah AES 192. Algoritma tersebut kalah pada file ke-0 dengan kecepatan 12,008 seconds serta dengan rasio 34,78\% lebih lambat, pada file ke-2 dengan kecepatan 75,019 seconds serta dengan rasio 27,89\% lebih lambat, pada proses download dan pada file ke-4 dengan kecepatan 36,237 seconds serta dengan rasio 18,37\% lebih lambat. Sedangkan pada proses upload AES 192 kalah pada file ke-0 dengan kecepatan 12,423 seconds serta dengan rasio 35,89\% lebih lambat, file ke-2 dengan kecepatan 76,345 seconds serta dengan rasio 22,68\% lebih lambat dan pada file ke-4 dengan kecepatan 37,398 seconds serta dengan rasio $21,83 \%$ lebih lambat.

Adapun beberapa saran untuk pengembangan penelitian selanjutnya yaitu melakukan pengujian lebih lengkap dengan tambahan algoritma Blowfish, RC4 dan IDEA dengan parameter yang diuji tidak hanya kecepatan tapi dengan kemanannya serta melakukan percobaan dengan perangkat asli/riil.

\section{REFERENSI}

[1] A. Rahmatulloh and R. Munir, "Pencegahan Ancaman Reverse Engineering Source Code PHP dengan Teknik Obfuscation Code pada Extension PHP," in Konferensi Nasional Informatika,

Permana, Perbandingan Algoritma Pada Teknologi Virtual Private Network (VPN) IPSec Terhadap Kecepatan Transfer Data 
2015.

[2] E. Ramaraj and S. Karthikeya, "A New Type of Network Security Protocol Using Hybrid Encryption in Virtual Private Networking," J. Comput. Sci., vol. 2, no. 9, pp. 672-675, 2009.

[3] G. Williams, “Apa itu VPN? Panduan Pemula Lengkap tentang VPN di 2019," 2019. [Online]. Available: https://id.wizcase.com/blog/apa-itu-vpn-panduan-bagi-pemula/. [Accessed: 03-Jul2019].

[4] O. Valentine, "VPN Usage and Trends Around the World in 2018," 2018. [Online]. Available: https://blog.globalwebindex.com/chart-of-the-day/vpn-usage-2018/. [Accessed: 21-Jul-2019].

[5] M. A. Mohamed, M. E. A. Abou-El-Seoud, and A. M. El-Feki, "A Survey of VPN Security Issues," Int. J. Comput. Sci. Issues, vol. 11, no. 4, pp. 106-111, 2014.

[6] I. AFRIANTO and E. B. SETIAWAN, "KAJIAN VIRTUAL PRIVATE NETWORK ( VPN ) SEBAGAI SISTEM PENGAMANAN ( Studi Kasus Jaringan Komputer Unikom )," Maj. Ilm. UNIKOM, vol. 12, no. 1, pp. 43-52, 2014.

[7] S. Kromodimoeljo, Teori dan Aplikasi KRIPTOGRAFI. SPK IT Consulting, 2009.

[8] G. Singh and S. Supriya, "A Study of Encryption Algorithms (RSA, DES, 3DES and AES) for Information Security,” Int. J. Comput. Appl., vol. 67, no. 19, pp. 33-38, 2013.

[9] A. J. Patel and A. Gandhi, "A SURVEY ON PERFORMANCE EVALUATION OF VPN," Int. J. Adv. Eng. Res. Dev., 2017.

[10] P. Venkateswari and D. T. Purusothaman, "Comparative Study of Protocols Used for Establishing VPN," Int. J. Eng. Sci. Technol., vol. 1, no. 3, p. 6, 2010.

[11] R. Kajal, D. Saini, and K. Grewal, "Virtual Private Network," Int. J. Adv. Res. Comput. Sci. Softw. Eng., vol. 2, no. 10, p. 2277, 2012.

[12] D. Boedi P, "Perbandingan Kinerja Ip Sec Dan Ssl,” Telematika, vol. 7, no. 1, 2015.

[13] I. Nugroho, B. Widada, and Kustanto, "Perbandingan Performansi Jaringan Virtual Private Network Metode Point To Point Tunneling Protocol ( Pptp ) Dengan Metode Internet Protocol Security," J. TIKomSiN, 2015.

[14] W. O. Zamalia, L. M. F. Aksara, and M. Yamin, "ANALISIS PERBANDINGAN PERFORMA QOS, PPTP, L2TP, SSTP DAN IPSEC PADA JARINGAN VPN MENGGUNAKAN MIKROTIK," semanTIK, 2018.

[15] B. Ardiyansyah, "IMPLEMENTASI IPSEC PADA VPN," Network, 2008.

[16] Rudol, "Implementasi Keamanan Jaringan Komputer Pada Virtual Private Network ( Vpn ) Menggungakan IPSec," Implementasi Keamanan Jar. Komput. Pada Virtual Priv. Netw. Menggungakan Ipsec, 2017.

[17] D. A. Sanjaya, I. Darmawan, and N. Widiyasono, "ANALISIS SIMULASI PERBANDINGAN TEKNOLOGI MPLS dan FRAME RELAY PADA LAYANAN VPN," $J$. Tek. Inform. Fak. Tek. Univ. Siliwangi, pp. 1-10, 2011.

[18] R. T. Prabowo and M. T. Kurniawan, "Analisis dan Desain Keamanan Jaringan Komputer dengan Metode Network Development Life Cycle (Studi Kasus: Universitas Telkom)," J. Rekayasa Sist. dan Ind., 2015.

[19] R. Kurniawan, "Analisis Dan Implementasi Desain Jaringan Hotspot Berbasis Mikrotik Menggunakan Metode NDLC (Network Development Life Cycle) Pada BPU Bagas Raya Lubuk Linggau," J. BETRIK, 2016.

[20] M. Syani and A. M. Ropi, "Analisis Dan Implementasi Network Security System Menggunakan Teknik Host-Based Intrusion Detection System (Hids) Berbasis Cloud Computing," Semin. Nas. Telekomun. dan Inform. (SELISIK 2018), 2018. 